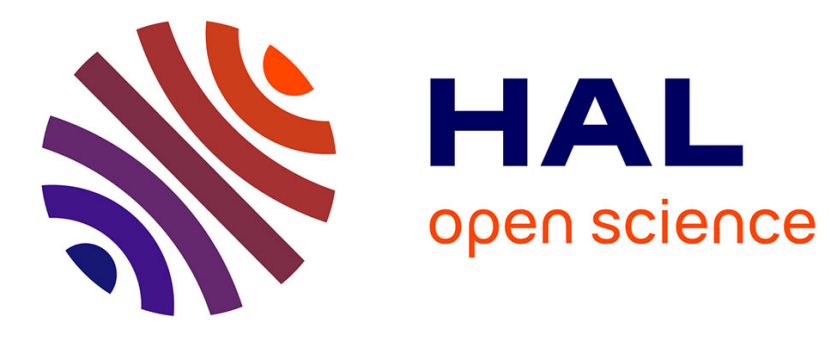

\title{
Potential and challenges of VLC based IPS in underground mines
}

Fabián Seguel, Ismael Soto, Pablo Adasme, Nicolas Krommenacker, Patrick Charpentier

\section{- To cite this version:}

Fabián Seguel, Ismael Soto, Pablo Adasme, Nicolas Krommenacker, Patrick Charpentier. Potential and challenges of VLC based IPS in underground mines. First South American Colloquium on Visible Light Communications, SACVLC 2017, Nov 2017, Santiago, Chile. hal-01666573

\section{HAL Id: hal-01666573 https://hal.science/hal-01666573}

Submitted on 18 Dec 2017

HAL is a multi-disciplinary open access archive for the deposit and dissemination of scientific research documents, whether they are published or not. The documents may come from teaching and research institutions in France or abroad, or from public or private research centers.
L'archive ouverte pluridisciplinaire HAL, est destinée au dépôt et à la diffusion de documents scientifiques de niveau recherche, publiés ou non, émanant des établissements d'enseignement et de recherche français ou étrangers, des laboratoires publics ou privés. 


\title{
Potential and Challenges of VLC based IPS in Underground Mines
}

\author{
Fabian Seguel $^{* \dagger}$, Ismael Soto*, Pablo Adasme*, \\ Nicolas Krommenacker ${ }^{\dagger}$ and Patrick Charpentier ${ }^{\dagger}$ \\ * Department of Electrical Engineering, \\ Universidad de Santiago de Chile, Av Libertador Bernardo O'Higgins 3363, CHILE \\ \{Fabian.seguelg, ismael.soto, pablo.adasme\}@usach.cl \\ $\dagger$ Lorraine University, CRAN, CNRS UMR 7039, Nancy, FRANCE \\ \{nicolas.krommenacker, patrick.charpentier\}@univ-lorraine.fr
}

\begin{abstract}
Chile is the largest copper producer in the world. In the world, almost $40 \%$ of copper is produced underground and it is expected that the activity will reach the $60 \%$ of the total mining activity. Because of this, there will be new challenges in terms of safety and productivity. Visible Light Communications (VLC) is a new technology capable to provide illumination and communication at the same time. This technology has shown high accuracy in localization and tacking for indoor scenarios. Nevertheless, most of the applications that can be found in literature assumes square rooms, no tilt receivers, and Line of Sight (LOS) link. In this paper we will address the problem of enabling Visible Light Communications (VLC) based Indoor Positioning System (IPS) in underground mines. Feasible link configurations and positioning topologies are studied throughout this paper. In addition to this, different localization methods are classified in two groups, i.e., range based and range free methods. Their performance in terms of accuracy and robustness as well as the constraints of each method will be analyzed for its usage in underground mines.
\end{abstract}

\section{INTRODUCTION}

Chile is the world leader producer of cooper. It is expected by 2020 that the largest open pit mine (Chuquicamata) will change its operation to underground. This, will pose new challenges in order to perform sustainable, safe and highly profitable mining process. To accomplish this purpose, industrial processes require reliable wireless communication systems for enabling mobility of dynamic actors and for transmission of different types of data equipment monitoring, maintenance labors, etc. Inside the tunnel, workers and machinery will be working together continuously. Localization and tracking of workers improves the safety of the operation since in case of an emergency, evacuation routes can be optimized in order to minimize the potential risks. Some countries, like the United States have already strengthened their safety standards and mine operators must have electronic tracking system [1]. Besides, localization and tracking of both, workers and mobile machinery, can lead to an optimization on the operation since its location information can be used by a central dispatch station to minimize the operation cost by sending the nearest idle worker or machine to the zone where it is required [2]. Since the traditional GPS system does not work on indoor scenarios because satellites signals cannot penetrate to confined places [3] some other alternatives has been proposed for localization in underground environments such as Radio frequency identification [4] and Zigbee [5] among others. Most of below named technologies uses the Radio Frequency (RF) portion of the Electro-magnetic (EM) spectrum to provide wireless communication. RF signals face some constraints when are used in underground mines. RF signals are affected by a large amounts of reflections, scattering, and shadowing. This, severely affect its propagation performance [6].

RF spectrum is just a small portion of the EM spectrum and, due to this, different frequency bands with different properties can be used to provide communication and localization. In particular, Visible Light Communications (VLC) technology has taken advantage among other types of optical wireless communications and it has found many applications. Visible light frequency is distributed in the range of 400 to $800 \mathrm{THz}$ while the radio waves are placed in $3 \mathrm{kHz}$ to $300 \mathrm{GHz}$. VLC technology transmits information by modulating the intensity of an optical source at a rate much more faster than the response time of human's eye making the change on the optical source unnoticeable. As a consequence, VLC technology is capable to provide illumination and wireless communication at the same time. In particular, in underground mines VLC based positioning systems can be installed inexpensively since this technology uses the existing lighting infrastructure with very few modifications [3].

To perform localization it is assumed that the wireless network contains a small number of special nodes with priory knowledge of their location called "Anchor Nodes". A second assumption is about topology edges, which is divided in two categories, range based and range free. Range based localization assumes that the device is equipped with extra hardware capable to determine precisely the range information. On the other hand, range free methods uses connectivity information to perform localization. Some of the range based techniques currently used on VLC applications are Receive Signal Strength (RSS) based, hybrid RSS-Angle of Arrival (AOA), AOA, Time of Arrival (TOA), hybrid TOA/RSS and Time Difference of Arrival (TDOA) among others which are summarized in few VLC localization surveys [3], [7]-[10]. On the other hand most of the range free methods has not been used in VLC based networks. Some of these methods 
are Distance-Vector Hop (DV-Hop) [11], Centroid [12] and Approximate Point in Triangulation (APIT) [13]. In this paper we will examine both localization schemes, i.e., range based and range free localization and their potential to perform localization in underground tunnels using the already deployed illumination infrastructure and considering the environmental constraints. The paper is organized as follows: In Section II the most commonly used VLC system configurations topologies as well as localization topologies will be described. In Section III range based and range free localization algorithms will be presented and detailed. In Section IV a comparative study between range based and range free localization algorithms for VLC based IPS in underground mines will be delivered. Finally, in Section V the main conclusions of the study as well as future research directions are shown.

\section{Visible Light COMMUNiCATIONS AND INDOOR POSITIONING SYSTEMS}

In this section VLC system configuration as well as indoor positioning topologies will be described. In order to provide wireless communication as well as positioning different system configurations of VLC link will be analyzed for it usage in underground mines in terms of users' mobility, robustness and coverage. In addition to this, based on the application, different indoor positioning systems topologies will be examined and their link requirements will be summarized in order to determine if VLC system is applicable on each topology and underground mines IPS requirements will be shown.

\section{A. Visible Light Communications System Configuration}

There are great number of considerations which must be taken into account when designing VLC networks. When VLC is used for confined environments, light will be reflected by the ceiling, walls and most of the objects inside the room. In addition to this, the optical signal will not pass through opaque barriers. Due to this, there are numerous ways to physically configure an optical link. Typically, They are grouped into four system configurations as shown in Figure 1.

Direct LOS path is commonly used in point-to-point communication links. The link is concentrated in a very narrow beam, this leads to a low power requirement. In addition to this, LOS link offers higher data rates with a transmission range from few meters to kilometers. LOS link is almost not affected by multipath signal distortion. Its usage for indoor applications could be limited because of its small coverage area [15]. Direct LOS path needs the alignment between emitter a receiver, because of this, this link configuration cannot be used in mobile applications.

On the other hand, nondirect LOS is commonly used for indoor applications. This link configuration is considered as the most flexible configuration. A combination of a wide light beam transmitters and a wide Field of View (FOV) receiver is used. Signal scattered from surfaces ca be used to increase the coverage area. This link configuration is suitable for point to multipoint broadcast applications because it offers robustness against shadowing and blockage. Transmitter must not be (b)

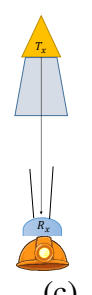

(c)

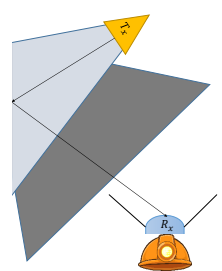

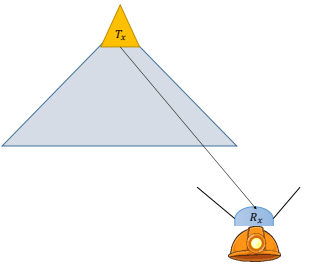

(d)
Fig. 1: Different systems configurations for VLC link, Photo detector (PD) is placed in the miner's helmet: (a) directed LOS, (b) nondirected LOS, (c) diffuse, and (d) tracked [14]

necessarily aligned with the receiver to perform the communication. Nevertheless, this type of link can may be affected by a high path loss and multipath distortion which leads to a detrimental effect on the performance of the system when dealing with high data rates. Besides, inter-cell interference increases when multiple sources are arranged in a small area due to the wide light beam of the transmitters. Nondirect LOS link is not suitable to operate in environments with intense ambient light [14], nevertheless, underground mines are far from being intensively illuminated.

Diffuse configuration proposed in [16] consists on a transmit-

TABLE I: Comparison of different VLC system configurations

\begin{tabular}{|l|l|l|l|}
\hline System Configuration & Mobility & Coverage & Cost \\
\hline Directed LOS & none & low & low \\
\hline Nondirected LOS & high & high & low \\
\hline Diffuse & very high & very high & low \\
\hline Tracked & high & high & high \\
\hline
\end{tabular}

ter pointing directly towards the ceiling or any surface within the room as shown in Figure $1 \mathrm{c}$ ). This link is the most suitable for optical Wireless Local Area Network (WLAN) and optical ad-hoc networks. Alignment between emitter and receiver is not necessary and is immune to blockage. It suffers from a multipath distortion and a high path loss which is increased by temporary obstructions [17]. The bit rate is limited and its performance is severely affected by ambient light.

In tracked systems emitter and receiver are aligned automatically by an electro-mechanical device. Nevertheless, these electro-mechanical devices are expensive. Electronic tracking schemes for this type of communication scheme has been previously proposed in [18]. In table I the main characteristics of each link configuration for enabling VLC based IPS are presented, i.e., mobility, coverage and cost. Diffuse and nondirected LOS link configurations have higher mobility and coverage compared to others configurations. Moreover, the 
cost of implementing a VLC system using nondirected LOS or diffuse link is low.

\section{B. Indoor Positioning Systems Topologies}

The architecture of the deployed network has an important effect on the performance of localization algorithm. Localization can be arranged in three different topologies [19] depending on where the localization is performed and the communication direction.

- Remote positioning: In remote positioning receivers at one or more localizations measure the signal provided by or reflected from the object to be positioned. Measurements performed by the receiver are communicated to a central station and the position is determined by combining this information. This topology of localization system is useful when there is another system running an application on a central site.

- Self Positioning: In self positioning systems the receiver measures the signal from the anchor nodes and uses the measurements to determine its own position.

- Indirect: A self-positioning receiver sends the information about the location to a remote site or vice versa. If the information is sent from the self-positioning receiver to the central station the system is known as Indirect remotepositioning and if the central station sent the information about the localization to the object to be positioned the system is known as Indirect self-positioning.

To perform remote positioning uplink is required since Mobile Nodes (MN) send information to the fixed Access Point (AP). On the other hand, to perform self-positioning only downlink is required. Finally, to perform indirect positioning both, uplink and downlink are required. Since VLC has been proposed mainly as downlink technology [20], [21] self-positioning or indirect self-positioning are feasible alternatives to perform positioning in underground mines using VLC. In table II a summary of link requirements, suitable technologies as well as the main issues to be overcome for implementing IPS in underground tunnels for the above mentioned topologies are shown. There is still many issues to be solved for using VLC

TABLE II: Topologies for VLC based IPS in underground mines

\begin{tabular}{|l|l|l|l|}
\hline Topology & $\begin{array}{l}\text { Link } \\
\text { Requirements }\end{array}$ & Technology & Issues \\
\hline $\begin{array}{l}\text { Remote } \\
\text { Position- } \\
\text { ing }\end{array}$ & Uplink & RF or IR & $\begin{array}{l}\text { Low performance } \\
\text { of RF systems. IR } \\
\text { needs fixed PD } \\
\text { devices placed in- } \\
\text { side the tunnel }\end{array}$ \\
\hline $\begin{array}{l}\text { Self Posi- } \\
\text { tioning }\end{array}$ & Downlink & VLC & $\begin{array}{l}\text { No information } \\
\text { about positioning } \\
\text { in central station }\end{array}$ \\
\hline Indirect & $\begin{array}{l}\text { Uplink and } \\
\text { Downlink }\end{array}$ & $\begin{array}{l}\text { VLC for down- } \\
\text { link and RF or IR } \\
\text { for uplink }\end{array}$ & $\begin{array}{l}\text { Full duplex com- } \\
\text { munication is re- } \\
\text { quired }\end{array}$ \\
\hline
\end{tabular}

for uplink since visible light can cause disturbance to users. Due to this, uplink is mainly provided by infrared or RF [22][24] and visible light is mainly used for downlink.

\section{Underground mines positioning systems requirements}

Based on the US safety standard for underground mines of 2006 [25] some IPS requirements have to be met in order to provide information about the position of workers inside the underground tunnel. The system must have a minimum accuracy of $60.96(\mathrm{~m})$ relative to a fixed point. In addition to this, it must have an update rate up to 60 seconds and it has to be used for maximum possible number of persons, including visitors, expected to be inside the tunnel.

\section{TOPOLOGY EDGES}

Most of the work done so far in the literature about range free VLC based IPS assume that there exist a high anchor node's density (LED lights) and MN can perceive more than 3 sources at each time. In this section, commonly used methods for VLC based IPS will be described and examined.

\section{A. Range based methods}

Range based methods assumes that the device is equipped with extra hardware capable to determine precisely the range information. The mainly used range based localization methods for VLC systems will be presented in this section, i.e., RSS, TDOA, AOA and TOA.

1) Received signal strength: The signal of VLC link gradually falls of in strength as the receiver moves further away from the light transmitter. If the relationship between distance and signal strength is known, i.e., $d_{s r}=f\left(P_{r}\right)$, where $d_{s r}$ is the distance between transmitter and receiver, $P_{r}$ is the received power and $f($.$) is a function that relates distance$ and received power, then, the RSS can be used to determine the distance $d_{s r}$. If there is signal strength information about several different based stations or targets, trilateration can be used to determine the position of the MN. This method mostly assume that there exist LOS link between emitter and receiver because it suffers detrimental effects when the reflected light is considered [26]. In addition to this, the received power depends also on the signal's received angle. In order to solve this problem a scaling factor RSS method was proposed in [27] when no other devices such as gyroscopes or accelerometers are incorporated at the receiver. Some other methods use PD arrays [28] and cross correlation function between transmitter and receiver [29] in order to deal with angle diversity in the receiver side. In general, RSS based method increases their accuracy when a large number of LEDs are perceived [30], multipath effects are neglected and non-tilt receivers are considered.

2) Time of arrival: This method uses the time it takes to Electro-magnetic (EM) waves to travel the distance between anchor node and receiver. Since the velocity of EM waves can be considered as constant the distance is determined by $d_{s} j=c \Delta t$ where $c$ is the speed of light, $\Delta t$ is the time it takes to the signal to travel between transmitter and receiver. In TOA the receiver's clock is somehow synchronized to the transmitter's clock in order to determine $\Delta t$ as shown in [31]. This system also assumes direct LOS communication and unlike RSS based methods it does not suffer detrimental effect 
TABLE III: Summary of VLC based IPS and their constraints in underground mines application

\begin{tabular}{|c|c|c|c|c|c|c|}
\hline Parameter & \multicolumn{4}{|c|}{ Range based } & \multicolumn{2}{|c|}{ Range free } \\
\hline Method & RSS & TOA & TDOA & $\mathrm{AOA}$ & Hop count & Neighborhood \\
\hline Acuraccy & $\begin{array}{l}\text { From } 0.01 \text { when } \\
\text { LOS link and no } \\
\text { multipath effect is } \\
\text { considered and up } \\
\text { to } 1[\mathrm{~m}] \text { with tilt re- } \\
\text { ceivers, multipath } \\
\text { and noise }\end{array}$ & $\begin{array}{l}0.02-0.06[\mathrm{~m}] \\
\text { when transmitter } \\
\text { and receiver } \\
\text { are assumed } \\
\text { to be perfectly } \\
\text { synchronized. } \\
\text { LOS link and no } \\
\text { multipath effects } \\
\text { are considered }\end{array}$ & $\begin{array}{l}0.01[\mathrm{~m}] \text { when LOS } \\
\text { link and noise free } \\
\text { communication are } \\
\text { considered. Up to } \\
\approx 0.7[\mathrm{~m}] \text { when } \\
\text { multipath, noise } \\
\text { and rising-falling } \\
\text { time of LED lights } \\
\text { are considered }\end{array}$ & $\begin{array}{l}0.05[\mathrm{~m}] \text { when } \\
\text { no tilt PD or } \\
\text { multiple PD array, } \\
\text { no multipath and } \\
\text { LOS link are } \\
\text { considered, and up } \\
\text { to } 0.3[\mathrm{~m}] \text { when } \\
\text { tilt receiver with } \\
\text { accelerometers is } \\
\text { used on tilt circular } \\
\text { PD array }\end{array}$ & $\begin{array}{l}\text { From several } \\
\text { meters up to few } \\
\text { centimeters can be } \\
\text { achieved assuming } \\
\text { full connectivity } \\
\text { of the Ad-Hoc } \\
\text { network }\end{array}$ & $\begin{array}{l}0.1 \quad[\mathrm{~m}] \text { using } \\
\text { angular diversity } \\
\text { of the transmitting } \\
\text { LED lights is } \\
\text { exploited to create } \\
\text { coverage area up } \\
\text { to } 2.5[\mathrm{~m}] \text { when } \\
\text { Cell ID is used }\end{array}$ \\
\hline Robustness & $\begin{array}{l}\text { Strongly decreases } \\
\text { when multipath ef- } \\
\text { fects and tilt re- } \\
\text { ceivers are consid- } \\
\text { ered. Diffuse link } \\
\text { configuration is not } \\
\text { feasible since pre- } \\
\text { cise ranging infor- } \\
\text { mation is required }\end{array}$ & $\begin{array}{l}\text { Strongly decreases } \\
\text { when multipath ef- } \\
\text { fects. Tilt receivers } \\
\text { has no effect on the } \\
\text { performance. Dif- } \\
\text { fuse link configura- } \\
\text { tion is not feasible } \\
\text { since precise rang- } \\
\text { ing information is } \\
\text { required }\end{array}$ & $\begin{array}{l}\text { Strongly decreases } \\
\text { when multipath ef- } \\
\text { fects is considered. } \\
\text { Tilt receivers has } \\
\text { no effect on the } \\
\text { performance. Dif- } \\
\text { fuse link configura- } \\
\text { tion is not feasible } \\
\text { since precise rang- } \\
\text { ing information is } \\
\text { required }\end{array}$ & $\begin{array}{l}\text { Strongly decreases } \\
\text { when multipath ef- } \\
\text { fects and tilt re- } \\
\text { ceivers are consid- } \\
\text { ered. Diffuse link } \\
\text { configuration is not } \\
\text { feasible since pre- } \\
\text { cise ranging infor- } \\
\text { mation is required }\end{array}$ & $\begin{array}{l}\text { Only connectivity } \\
\text { information is } \\
\text { required. Tilt } \\
\text { receivers as well } \\
\text { as Non-Directed } \\
\text { LOS and diffuse } \\
\text { links can be used. } \\
\text { Accuracy strongly } \\
\text { depends on the } \\
\text { node density and } \\
\text { connectivity of the } \\
\text { network }\end{array}$ & 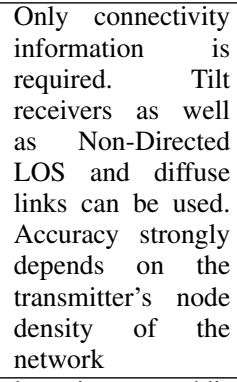 \\
\hline Cost & $\begin{array}{l}\text { low since no addi- } \\
\text { tional hardware is } \\
\text { required in the re- } \\
\text { ceiver }\end{array}$ & $\begin{array}{l}\text { medium since } \\
\text { special hardware } \\
\text { for synchronization } \\
\text { and time } \\
\text { measurement } \\
\text { is required }\end{array}$ & $\begin{array}{l}\text { medium since spe- } \\
\text { cial hardware for } \\
\text { time measurement } \\
\text { is required }\end{array}$ & $\begin{array}{l}\text { medium since spe- } \\
\text { cial hardware for } \\
\text { angle measurement } \\
\text { is required }\end{array}$ & $\begin{array}{l}\text { medium since spe- } \\
\text { cial hardware for } \\
\text { note-to-node com- } \\
\text { munication is re- } \\
\text { quired }\end{array}$ & $\begin{array}{l}\text { low since no addi- } \\
\text { tional hardware is } \\
\text { required in the re- } \\
\text { ceiver }\end{array}$ \\
\hline
\end{tabular}

when tilt receivers are considered. Nevertheless, synchronization between transmitter and receiver is a difficult task.

3) Time difference of arrival: TDOA uses the difference on the arrival's time of the signals transmitted by fixed lights to the $\mathrm{MN}$ or by measuring a single or multiple sources in a multiple PD array at the receiver. If the distance between transmitters is known then, the distance between each transmitter and the receiver can be obtained and, subsequently, the position of the mobile node. Some methods assume a single PD receiver who measures the difference on the arrival time from multiple light sources with known positions. In order to differentiate the signals Time Division Multiplexing (TDM) or Frequency Division Multiplexing (FDM) techniques are used. The considered method assumes that there exist LOS link between transmitter and receiver. In addition to this, at least three sources has to be sensed by the MN to perform localization [32]-[34]. An interesting localization method is proposed in [35] where a 2-PD receivers and two light sources are used to perform localization in a infrastructure to vehicle network. Another advantage over TOA method is that TDOA does not need synchronization between transmitter and receiver.

4) Angle of arrival: For using AOA method the angle in which different optical signals arrive to a single PD receiver have to be measured or alternatively, the AOA of a single or multiple sources to a multiple PD array. For doing this, LOS link is considered as de-facto system configuration in VLC. Positioning using AOA can be obtained by using a minimum of 2 LED lights for 2-D localization unlike above mentioned methods where at least 3 sources are required. The difference on the AOA can be inferred from the difference of the received power from multiple sources in a single PD or by using a PD array. Besides considering LOS link, some applications assumes that the transmitter and receiver are aligned in the same X-Y plane, thus, incidence angles and irradiance angles are equal. Other sensors such as accelerometers can be used to compensate the effect of tilt receivers in combination with multiple PD array [36]. Nevertheless, using these sensors at the receiver side will reduce the battery lifetime in mobile devices. In addition to this, AOA methods suffer high detrimental effect when non-LOS link and reflections are considered.

\section{B. Range free methods}

Range free localization uses the connectivity information between the nodes. The Anchor nodes with prior knowledge of their own position are commonly fixed nodes of the network while mobile nodes uses the information to estimate their position. In this scheme ranging measurements are not needed, due to this, range free localization has a lower cost and higher robustness since connectivity information is not easily affected by the environment. Range free methods can be divided mainly in two groups, hop-count methods and neighborhood methods.

1) Hop count methods: In order to determine the position of a mobile node, hop count method propagates the anchor node information throughout the network. By doing this, MN that are not directly communicated with the anchor node can have a rough estimation of their distance to the nearest anchor nodes by counting the number of hops between them. Adhoc wireless network is a mandatory requirement for this 
type of algorithms since mobiles nodes must to be able to communicate between them. Hybrid VLC-RF techniques has been studied where VLC anchor nodes are considered and communication between $\mathrm{MN}$ is performed by using a RF method such as Zigbee or Bluetooth [37]-[39]. This method is affected by node density because communication between $\mathrm{MN}$ and anchor nodes has to be ensured.

2) Neighborhood: Neighborhood methods does not use ranging information to determine $\mathrm{MN}$ position. In addition to this, this type of methods do not require an ad-hoc network or WSN implementation since they use the received anchor node's information to perform localization. This, pose a constraint to the system since the $\mathrm{MN}$ has to be aware about the position of one or more anchors to perform localization. Coarse grained localization can be obtained when a large number of anchor nodes is considered. The most used neighborhood methods are Centroid [12], Approximate Point in Triangulation (APIT) [13]. A neighborhood method for underground mines was proposed in [40]. LOS link was considered. Higher accuracy is obtained by increasing the overlapping regions of LED lights.

\section{Discussion}

When using range based methods for localization in underground mines tunnels tilt transmitters and receivers, multipath effects, low anchor node's density and diffuse link has to be considered as shown in Figure 2 (a). Luminaries deployed inside the tunnel can be placed in the top of the tunnel or in the walls in order to facilitate maintenance labors. When luminaries are placed in the tunnel's walls tilt transmitters has to be considered. In addition to this, machinery inside the mine can cause shadowing as shown in Figure 2 (b). Due to this, the signal received by workers inside the mine will be provided by the reflection of the light inside the tunnel (diffuse link). RSS, TOA, TDOA and AOA based methods suffer detrimental effects when multipath or diffuse link is considered. These methods are unfeasible to be deployed in working zones inside the tunnel since machinery and workers co-exist and the VLC link will suffer from shadowing. Tilt receivers have to be considered since workers will be performing labors inside the tunnel. This, will reduce the accuracy of AOA and RSS based methods. Inside the tunnel, low anchor node's density exists and RSS, TDOA and TOA methods need at least 3 LED to perform localization. On the other hand, when using AOA based method only two transmitters are required to be sensed to perform 2-D localization.

Range free algorithms are not susceptible to multipath effect, diffuse link conditions and tilt transmitters or receivers. Nevertheless, for implementing hop-based localization there must be connection between the $\mathrm{MN}$ in order to increase the accuracy of the system. On the other hand, neighborhood methods uses only anchor nodes to estimate the position of the mobile nodes. Higher accuracy can be achieves by increasing the number of LED lights. Nevertheless, an accuracy of at least $60.96(\mathrm{~m})$ is required for underground mines. A brief summary of each (a)

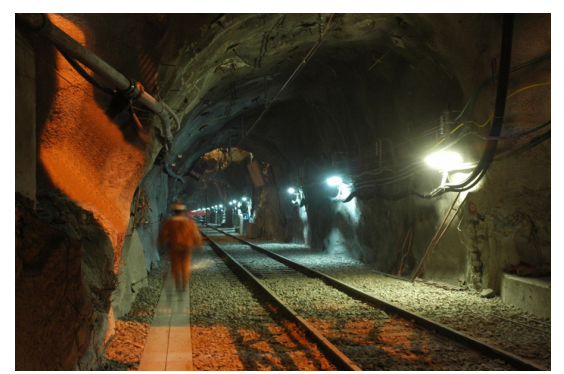

(b)

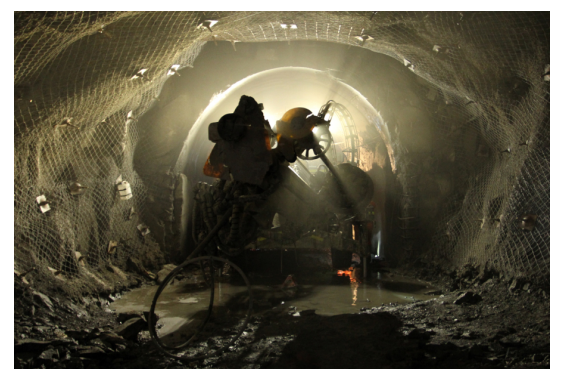

Fig. 2: El Teniente underground mine light deployment (a) Transportation tunnel (b) Machinery working inside the tunnel

technique is shown in Table III where accuracy, robustness and cost for each localization method is presented.

\section{CONCLUSIONS AND FUTURE WORK}

Throughout this paper different considerations for enabling VLC based IPS systems in underground mines where pointed out and discussed. Mainly, three subjects where studied, i.e., VLC system configuration, IPS topologies and localization methods. Since in underground mines workers and machinery works alongside mainly two VLC system configuration have to be considered, nondirected LOS and diffuse links. When this type of system configuration is assumed, range based localization algorithms lacks of accuracy since they suffer from diffuse link on ranging measurements.

Two different IPS topologies can be considered for using VLC systems in underground mines, these are, self-positioning and indirect positioning. In particular indirect positioning is the one that has to be addressed to increase the safety by sending position information to a central station. Finally, we conclude that range free algorithms can be a suitable method for VLC based IPS system in underground mines since these methods are robust to LOS link shadowing, multipath effects and the cost is lower since they do not require additional hardware infrastructure to perform ranging measurements. In future work a novel VLC channel in underground mines will be proposed, power distribution, channel impulse response and time delay spread will be obtained. In addition to this, performance of range based algorithms under this VLC channel will be evaluated. 


\section{ACKNOWLEDGMENT}

This work was funded by the Beca Doctorado Nacional 2016 CONICYT PFCHA/21161397, the USACH DICYT Projects 061413SG, 061513VC - DAS and 061713AS, CORFO 14IDL2 - 29919

\section{REFERENCES}

[1] A. Hrovat, G. Kandus, and T. Javornik, "A Survey of Radio Propagation Modeling for Tunnels," IEEE Communications Surveys \& Tutorials, vol. 16, no. 2, pp. 658-669, 2014.

[2] J. Ferrer-Coll, P. Angskog, H. Shabai, J. Chilo, and P. Stenumgaard, "Analysis of wireless communications in underground tunnels for industrial use," IECON Proceedings (Industrial Electronics Conference), pp. 3216-3220, 2012.

[3] T.-H. Do and M. Yoo, "An in-Depth Survey of Visible Light Communication Based Positioning Systems," Sensors, vol. 16, no. 5, p. 678, 2016.

[4] S. R. Rusu and M. J. D. Hayes, "Localization in Large-Scale Underground Environments with RFID," 24th Canadian Conference on Electrical and Computer Engineering, pp. 1140-1143, 2011.

[5] H. Xu, F. Li, and Y. Ma, "A ZigBee-based miner localization system," Proceedings of the 2012 IEEE 16th International Conference on Computer Supported Cooperative Work in Design, CSCWD 2012, pp. 919924, 2012

[6] Z.-M. Wang and Y. Zheng, "The Study of the Weighted Centroid Localization Algorithm Based on RSSI," in 2014 International Conference on Wireless Communication and Sensor Network. IEEE, dec 2014, pp. $276-279$.

[7] C. Wang, L. Wang, X. Chi, S. Liu, W. Shi, and J. Deng, "The research of indoor positioning based on visible light communication," China Communications, vol. 12, no. 8, pp. 85-92, 2015.

[8] T. H. Do and M. Yoo, "Potentialities and challenges of VLC based outdoor positioning," International Conference on Information Networking, vol. 2015-Janua, pp. 474-477, 2015.

[9] N. U. Hassan, A. Naeem, M. A. Pasha, T. Jadoon, and C. Yuen, "Indoor Positioning Using Visible LED Lights," ACM Computing Surveys, vol. 48 , no. 2 , pp. 1-32, nov 2015.

[10] K. Yan, H. Zhou, H. Xiao, and X. Zhang, "Current status of indoor positioning system based on visible light," in 2015 15th International Conference on Control, Automation and Systems (ICCAS). IEEE, oct 2015 , pp. 565-569.

[11] D. Niculescu and B. Nath, "Ad hoc positioning system (APS)," in GLOBECOM'01. IEEE Global Telecommunications Conference (Cat. No.01CH37270), vol. 5. IEEE, 2001, pp. 2926-2931.

[12] N. Bulusu, J. Heidemann, and D. Estrin, "GPS-less low-cost outdoor localization for very small devices," IEEE Personal Communications, vol. 7 , no. 5, pp. 28-34, 2000 .

[13] T. He, C. Huang, B. M. Blum, J. A. Stankovic, and T. Abdelzaher, "Range-free localization schemes in large scale sensor networks," in Proceedings of the 9th annual international conference on Mobile computing and networking - MobiCom '03. New York, New York, USA: ACM Press, 2003, p. 81.

[14] Z. Ghassemlooy, W. Popoola, and S. Rajbhandari, Optical wireless

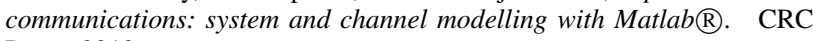
Press, 2012.

[15] D. Biosca Rojas and J. L. López Presmanes, "Generalización del algoritmo de trazado de rayos de Monte Carlo modificado para el cálculo de la respuesta al impulso de canales ópticos infrarrojos en interiores," Universidad, Ciencia y Tecnología, vol. 9, no. 33, pp. 17-25, 2005.

[16] F. Gfeller and U. Bapst, "Wireless in-house data communication via diffuse infrared radiation," Proceedings of the IEEE, vol. 67, no. 11, pp. 1474-1486, 1979.

[17] J. Kahn, W. Krause, and J. Carruthers, "Experimental characterization of non-directed indoor infrared channels," IEEE Transactions on Communications, vol. 43, no. 2/3/4, pp. 1613-1623, feb 1995.

[18] D. Wisely, "A $1 \mathrm{Gbit} / \mathrm{s}$ optical wireless tracked architecture for ATM delivery," in IEE Colloquium on Optical Free Space Communication Links, vol. 1996. IEE, 1996, pp. 14-14.

[19] C. Drane, M. Macnaughtan, and C. Scott, "Positioning GSM telephones," IEEE Communications Magazine, vol. 36, no. 4, pp. 46-54, 59, apr 1998.
[20] R. Zhang, J. Wang, Z. Wang, Z. Xu, C. Zhao, and L. Hanzo, "Visible light communications in heterogeneous networks: Paving the way for user-centric design," IEEE Wireless Communications, vol. 22, no. 2, pp. 8-16, apr 2015.

[21] C. Chen, D. A. Basnayaka, and H. Haas, "Downlink performance of optical attocell networks," Journal of Lightwave Technology, vol. 34, no. 1, pp. 137-156, 2016.

[22] R. Perez-Jimenez, J. Rufo, C. Quintana, J. Rabadan, and F. J. LopezHernandez, "Visible light communication systems for passenger in-flight data networking," in 2011 IEEE International Conference on Consumer Electronics (ICCE). IEEE, jan 2011, pp. 445-446.

[23] P. H. Pathak, X. Feng, P. Hu, and P. Mohapatra, "Visible Light Communication, Networking, and Sensing: A Survey, Potential and Challenges," IEEE Communications Surveys and Tutorials, vol. 17, no. 4, pp. 20472077, 2015.

[24] D. Karunatilaka, F. Zafar, V. Kalavally, and R. Parthiban, "LED Based Indoor Visible Light Communications: State of the Art," IEEE Cоттиnications Surveys \& Tutorials, vol. 17, no. 3, pp. 1649-1678, 2015.

[25] 109th Congress, "Mine Improvement and New Emergency Response," pp. 109-236, 2006

[26] W. Gu, M. A. Kashani, and M. Kavehrad, "Multipath Reflections Analysis on Indoor Visible Light Positioning System," apr 2015.

[27] H.-S. Kim, D.-R. Kim, S.-H. Yang, Y.-H. Son, and S.-K. Han, "An Indoor Visible Light Communication Positioning System Using a RF Carrier Allocation Technique," Journal of Lightwave Technology, vol. 31, no. 1, pp. 134-144, jan 2013.

[28] Se-Hoon Yang, Eun-Mi Jung, and Sang-Kook Han, "Indoor Location Estimation Based on LED Visible Light Communication Using Multiple Optical Receivers," IEEE Communications Letters, vol. 17, no. 9, pp. 1834-1837, sep 2013.

[29] W. Liu, C. Yang, Y. Chen, Q. Yang, and D. Zhang, "An Indoor Positioning System Based on Cross-correlation in Visible Light Communication," in Asia Communications and Photonics Conference 2014. Washington, D.C.: OSA, nov 2014, p. AW3G.4.

[30] T. Nguyen, Y. M. Jang, and Y. Min Jang, "Highly Accurate Indoor Three-Dimensional Localization Technique in Visible Light Communication Systems," The Journal of Korean Institute of Communications and Information Sciences, vol. 38, sep 2013.

[31] T. Q. Wang, Y. A. Sekercioglu, A. Neild, and J. Armstrong, "Position Accuracy of Time-of-Arrival Based Ranging Using Visible Light With Application in Indoor Localization Systems," Journal of Lightwave Technology, vol. 31, no. 20, pp. 3302-3308, oct 2013.

[32] Young Hoon Choi, In Hwan Park, Yoon Hyun Kim, and J. Y. Kim, "Novel LBS technique based on visible light communications," in 2012 IEEE International Conference on Consumer Electronics (ICCE). IEEE, jan 2012, pp. 576-577.

[33] T.-H. Do and M. Yoo, "TDOA-based indoor positioning using visible light," Photonic Network Communications, vol. 27, no. 2, pp. 80-88, apr 2014.

[34] Y. Kim, Y. Shin, and M. Yoo, "VLC-TDOA Using Sinusoidal Pilot Signal," in 2013 International Conference on IT Convergence and Security (ICITCS). IEEE, dec 2013, pp. 1-3.

[35] R. Roberts, P. Gopalakrishnan, and S. Rathi, "Visible light positioning: Automotive use case," in 2010 IEEE Vehicular Networking Conference. IEEE, dec 2010, pp. 309-314.

[36] M. Yasir, S.-W. Ho, and B. N. Vellambi, "Indoor Position Tracking Using Multiple Optical Receivers," Journal of Lightwave Technology, vol. 34, no. 4, pp. 1166-1176, feb 2016.

[37] M. Nakajima and S. Haruyama, "Indoor navigation system for visually impaired people using visible light communication and compensated geomagnetic sensing," in 2012 1st IEEE International Conference on Communications in China (ICCC). IEEE, aug 2012, pp. 524-529.

[38] X. Liu, H. Makino, S. Kobayashi, and Y. Maeda, "Design of an Indoor Self-Positioning System for the Visually Impaired - Simulation with RFID and Bluetooth in a Visible Light Communication System," in 2007 29th Annual International Conference of the IEEE Engineering in Medicine and Biology Society. IEEE, aug 2007, pp. 1655-1658.

[39] Y. U. Lee, S. Baang, J. Park, Z. Zhou, and M. Kavehrad, "Hybrid positioning with lighting LEDs and Zigbee multihop wireless network," B. Dingel, R. Jain, and K. Tsukamoto, Eds., jan 2012, p. 82820L.

[40] N. Krommenacker, O. C. Vasquez, M. D. Alfaro, and I. Soto, "A selfadaptive cell-ID positioning system based on visible light communications in underground mines," in 2016 IEEE International Conference on Automatica (ICA-ACCA). IEEE, oct 2016, pp. 1-7. 